\title{
Is laparoscopic ventral rectopexy a good treatment option for rectal prolapse?
}

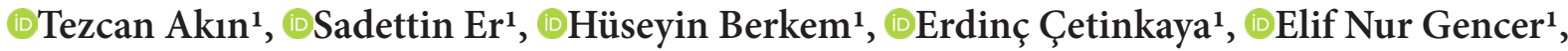

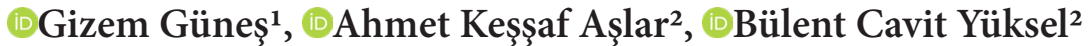 \\ ${ }^{1}$ Ankara City Hospital, Department of General Surgery, Ankara, Turkey \\ ${ }^{2}$ Health Sciences University Ankara City Hospital, Department of General Surgery, Ankara, Turkey
}

Cite this article as: Akın T, Er S, Berkem H, et al. Is laparoscopic ventral rectopexy a good treatment option for rectal prolapse? Anatolian Curr Med J 2022; 4(1); 108-112.

\begin{abstract}
Aim: Laparoscopic ventral rectopexy (LVR) is one of the most commonly performed procedures in the treatment of rectal prolapse (RP). This study aimed to evaluate postoperative changes in the incontinence status and short-term functional outcomes of patients with RP who underwent LVR.

Material and Method: This study included 15 patients who underwent LRV with the diagnosis of RP between January 2017 and June 2021 at Health Sciences University Ankara Numune Training and Research Hospital and Ankara City Hospital. Data were obtained by retrospectively examining the electronic records of the patients. The Wexner incontinence score (WIS) was calculated preoperatively and postoperatively by contacting the patients by phone at six months after the operation. In addition, the constipation status of the patients and whether they had recurrence of RP were questioned.

Results: The mean age of the 15 patients included in the study was 55 (range, 30-81) years. Twelve (80\%) patients were female and three $(20 \%)$ were male. When the preoperative and postoperative WISs of the patients were compared, the latter was statistically significantly lower than the former $(\mathrm{p}=0.002)$. Among the $10(66.7 \%)$ patients who had constipation in the preoperative period, this complaint was resolved in four (40\%), but new-onset constipation was detected in two (40\%) of the five $(33.3 \%)$ patients without preoperative constipation. The recurrence of RP was observed in only one (6.7\%) patient in the postoperative follow-up.

Conclusion: Considering the short-term outcomes in the patients who underwent LRV for RP, it can be concluded that LVR is a good option in this patient group, with a low recurrence rate and satisfactory improvement in incontinence.
\end{abstract}

Keywords: Rectal prolapsus, laparoscopic ventral rectopexy, incontinence, constipation

\section{INTRODUCTION}

Rectal prolapse (RP) or anal procidentia is a debilitating disease that greatly affects the quality of life and characterized by the intussusception of the rectal mucosa (mucosal prolapse) or all the layers of the rectum (complete rectal prolapse) along the anal canal $(1,2)$. When the prolapsed segment of the rectum is limited within the anal canal, it is called internal RP or rectal intussusception, and if it protrudes outside the anal orifice, it is referred to as external prolapse (3). In complete RP, where the rectal folds are seen outside the anal canal as concentric circles, the rectum and all its layers protrude outside the anal canal, while partial RP presents with the protrusion of only the rectal mucosa (4).

The etiology of RP, which is mostly seen in women and peaks in the seventh decade, has not yet been clearly elucidated, but redundant sigmoid colon, deep cul-de-sac, and diastasis of the levator ani muscle are the most common associated pathologies (5). While patients usually complain of fecal incontinence, which is considered to be the result of the chronic stretching of the anal sphincter and sustained stimulation of the rectoanal inhibitory reflex by the prolapsed tissue, other symptoms such as constipation, pain, and bloody mucus in stool can also be observed (5).

In the literature, many methods have been described for the treatment of RP, with the main treatment method being surgery which can be applied through perineal and abdominal (open or minimally invasive) routes, and the method to be used in the treatment is determined based on the patient's age, bowel function (constipation 
or incontinence) and comorbidities, as well as the experience and preference of the surgeon (6). To date, there has been no convincing evidence of the superiority of one procedure over another in terms of recurrence, functional improvement, or quality of life (7). An ideal surgical treatment for external and/or internal RP should correct anatomical abnormalities and relieve associated symptoms ranging from obstructive defecation to fecal incontinence (8). Ventral rectopexy (VR), first described by D'Hoore et al. in 2004, soon gained popularity as a treatment of choice for patients with RP (3).

VR is mostly performed with the laparoscopic method, in which Denonvillier's fascia is dissected without posterior rectal mobilization, and anterior rectal mobilization is provided before the synthetic mesh is fixed between the distal rectum and the sacrum (2). Laparoscopic VR (LVR) is increasingly acknowledged as an effective surgical treatment for posterior pelvic floor dysfunctions, such as external full-thickness RP, internal rectal intussusception, enteroceles, and complex rectoceles (9).

It has been shown that LVR provides $70-90 \%$ improvement in fecal incontinence complaints and 60$80 \%$ improvement in obstructive defecation complaints in patients with RP, and in addition to improvement in quality of life and incontinence, it results in $40 \%$ to $50 \%$ improvement in constipation scores $(9,10)$.

The aim of this retrospective study was to evaluate postoperative changes in the incontinence status and short-term functional outcomes of patients who underwent LVR with the diagnosis of a rectocele and RP.

\section{MATERIAL AND METHOD}

The study was started after receiving approval from the No 1 Clinical Research Ethics Committee of Ankara City Hospital (Date: 03.11.2021, Decision No: E1-21-2123). All procedures were carried out in accordance with the ethical rules and the principles of the Declaration of Helsinki.

\section{Patient Data}

This study was conducted by retrospectively examining the electronic records of the demographic data of patients who underwent LRV with the diagnosis of RP in Health Sciences University Ankara Numune Training and Research Hospital and Ankara City Hospital between January 2017 and June 2021. In order to evaluate the patients' continence status and lifestyle alteration, their preoperative and postoperative Wexner incontinence scores (WISs) were calculated and recorded by contacting them by phone at six months after the operation. In the calculation of WIS, each of the parameters of solid, liquid and gas incontinence, requirement of pad use, and lifestyle alteration was rated from 0 to 4 , and an evaluation was made over a total of 0 to 20 points ( $0=$ best score, 20=worst score) (Table 1) (11). Patients with complete RP confirmed by physical examination findings were included in the study. Difficult, unsatisfactory, or infrequent defecation (fewer than 3 bowel movements per week) was evaluated as constipation. Patients with inflammatory bowel disease, history of major abdominal surgery, diverticular disease, connective tissue disease, morbid obesity and comorbidities such as severe heart and kidney disease were not included in the study.

\begin{tabular}{|c|c|c|c|c|c|}
\hline \multirow{2}{*}{$\begin{array}{l}\text { Type of } \\
\text { incontinence }\end{array}$} & \multirow{2}{*}{ Never } & \multicolumn{3}{|c|}{ Frequency } & \multirow{2}{*}{ Always } \\
\hline & & Rarely & Sometimes & Usually & \\
\hline Solid & 0 & 1 & 2 & 3 & 4 \\
\hline Liquid & 0 & 1 & 2 & 3 & 4 \\
\hline Gas & 0 & 1 & 2 & 3 & 4 \\
\hline Pad requirement & 0 & 1 & 2 & 3 & 4 \\
\hline Lifestyle alteration & 0 & 1 & 2 & 3 & 4 \\
\hline
\end{tabular}

\section{Statistical Analysis}

All statistical analyses were performed using the Statistical Package for the Social Sciences (SPSS) (version 17.0, SPSS Inc., Chicago, IL, USA). Data for continuous variables were expressed as mean \pm standard deviation. Nominal values were analyzed using the Wilcoxon signed-rank test and Fisher's exact test and expressed as \%. A p value of $<0.05$ was considered statistically significant.

\section{RESULTS}

The mean age of the 15 patients included in the study was 55 (range, $30-81$ ) years. Twelve $(80 \%)$ patients were female and three $(20 \%)$ were male. While there was no systemic disease in nine patients, two patients had only hypertension (HT), one had HT and diabetes mellitus (DM), one had HT, DM and asthma, one had HT and asthma, and one had only asthma. The preoperative WIS of the patients was 0 in three $(20 \%)$ patients, 3 in two $(13.3 \%), 4$ in one $(6.7 \%), 5$ in one $(6.7 \%), 8$ in three $(20 \%), 9$ in one $(6.7 \%), 11$ in one $(6.7 \%), 15$ in one $(6.7 \%), 18$ in one $(6.7 \%)$, and 19 in one $(6.7 \%)$. The postoperative WIS was 0 in $10(66.6 \%)$ patients, 2 in one $(6.7 \%), 3$ in two (13.3\%), and 4 in two (13.3\%). The demographic data and preoperative and postoperative WISs of the patients are summarized in Table 2 . When the preoperative and postoperative WISs were compared, it was seen that the latter was statistically significantly lower than the former $(\mathrm{p}=0.002)$ (Table 3). Constipation was present in $10(66.6 \%)$ patients preoperatively and eight $(53.3 \%)$ patients postoperatively, indicating no statistically significant change $(\mathrm{p}>0.05)$. Postoperative 
constipation was resolved in four (40\%) of the 10 patients with constipation in the preoperative period, but newonset constipation was detected in two (40\%) of the five patients without preoperative constipation. The recurrence of RP developed in only one $(6.7 \%)$ patient in the postoperative follow-up.

\begin{tabular}{|c|c|c|}
\hline Age [Mean (min-max)] & \multicolumn{2}{|c|}{$55(30-81)$} \\
\hline \multicolumn{3}{|l|}{ Gender (\%) } \\
\hline Male & \multicolumn{2}{|c|}{$3(20)$} \\
\hline Female & \multicolumn{2}{|c|}{$12(80)$} \\
\hline WIS (\%) & $\underset{\mathbf{n}}{\text { Preoperative }}$ & $\underset{\mathbf{n}}{\text { Postoperative }}$ \\
\hline 0 & $3(20)$ & $10(66.6)$ \\
\hline 1 & - & - \\
\hline 2 & - & $1(6.7)$ \\
\hline 3 & $2(13.3)$ & $2(13.3)$ \\
\hline 4 & $1(6.7)$ & $2(13.3)$ \\
\hline 5 & $1(6.7)$ & - \\
\hline 6 & - & - \\
\hline 7 & - & - \\
\hline 8 & $3(20)$ & - \\
\hline 9 & $1(6.7)$ & - \\
\hline 10 & - & - \\
\hline 11 & $1(6.7)$ & - \\
\hline 12 & - & - \\
\hline 13 & - & - \\
\hline 14 & - & - \\
\hline 15 & $1(6.7)$ & - \\
\hline 16 & - & - \\
\hline 17 & - & - \\
\hline 18 & $1(6.7)$ & - \\
\hline 19 & $1(6.7)$ & - \\
\hline 20 & - & - \\
\hline
\end{tabular}

\begin{tabular}{|c|c|c|c|}
\hline & Preoperative & Postoperative & p \\
\hline WIS $(n=15)($ median \pm SD $)$ & $7.4 \pm 6.22$ & $1.7 \pm 1.62$ & $0.002^{*}$ \\
\hline Constipation (\%) & $10(66.7)$ & $8(53.3)$ & $>0.05$ \\
\hline
\end{tabular}

\section{DISCUSSION}

Abdominal (open/laparoscopic) and perineal surgical methods have been defined in the surgical treatment of $\mathrm{RP}$, and the surgical treatment procedure to be applied is selected based on the patient's age, comorbidities, type of $\mathrm{RP}$, and patient preference. The aim of surgical treatment is not only to correct the anatomical problem but also to resolve anorectal functional problems. Contrary to abdominal operations, anatomical restoration may not be achieved in perineal procedures due to the inability to achieve adequate exposure for the pelvic part of the rectum and other pelvic organs; however, pelvic approaches continue to be an appropriate surgical option in high-risk elderly patients (12). With the introduction of minimally invasive surgical procedures, abdominal procedures have been increasingly performed, but the type of abdominal procedure associated with improved postoperative functional outcomes remains unclear (13).

Today, LVR is performed by many pelvic floor surgeons in the treatment of symptomatic rectoceles, as well as that of internal and external RP (10). In a prospective randomized study, it was reported that this minimally invasive surgery had certain advantages over the open approach, such as less postoperative pain, shorter hospital stay, faster recovery, and most importantly a lower postoperative complication rate (14). The safe and satisfactory results of LVR have contributed to its popularity and preference among colorectal surgeons across the world, but there are still concerns pertaining to mesh-related complications, its suitability in some patient groups such as male patients, and recurrence of $\mathrm{RP}$ in the long term (3).

Although abdominal operations appear to have a lower recurrence rate compared to perineal operations, a Cochrane database review including 15 randomized controlled trials comparing 1,007 patients reported no significant difference in recurrence between the two approaches (15). However, in an original article, the recurrence rate was reported as 4\% (0-6\%) in abdominal rectopexy and 18\% (4-38\%) in perineal approaches (14). Recurrence rates after LVR are generally low, being reported as $0 \%-15 \%$ in a systematic review (10). Low recurrence rates after rectopexy have been generally observed in studies with short follow-up periods, and studies with a follow-up period exceeding 15 years are rare. Nevertheless, many publications suggest that recurrence increases over time (16). Although studies on the optimal approach to recurrent rectal prolapse repair are conflicting, abdominal approaches are also frequently used to repair rectal prolapse recurrence (4). Steele et al. reported that patients who underwent an abdominal approach for recurrent rectal prolapse had significantly fewer re-recurrences than those who had a perineal procedure (15\% versus $37 \%)(17)$. In our study, recurrence developed in only one $(6.7 \%)$ patient according to the short-term (six-months) results. This is consistent with the literature. The patient was opereted with a perineal approach for recurrence.

Approximately 25\%-50\% of patients with RP have constipation complaints (15). Abdominal procedures are associated with higher postoperative morbidity and may have adverse side effects, such as postoperative constipation (14). LVR using the anterior approach with limited rectal mobilization without lateral dissection, 
as defined by D'Hoore and Penninck in 2004, reduces the incidence of postoperative constipation when compared with posterior rectopexy (18). Posterior and lateral rectum dissection is not performed in LVR, and therefore its greatest advantage can be considered as the prevention of autonomic denervation and postoperative constipation (1). In a meta-analysis, improvement rates in constipation complaints after LVR were reported to vary between $33 \%$ and $100 \%$ in eight studies (3). In our study, constipation was present in $10(66.7 \%)$ patients preoperatively and eight (53.3\%) patients postoperatively ( $\mathrm{p}>0.05)$. Postoperative constipation complaints disappeared in four (40\%) patients with preoperative constipation, whereas new-onset constipation developed in two (40\%) patients without preoperative constipation. Despite the low number of our patients, it can be stated that an effective treatment method is still controversial considering the high rate of constipation and the wide variety of surgical treatment options in these patients.

Incontinence associated with complete rectal prolapse has been attributed not only to the intermittent activation of the rectoanal reflex due to RP but also to sphincter dilation due to pudendal nerve neuropathy caused by prolapse, and fecal incontinence complaints are reported to decrease by up to $90 \%$ after LVR (19). Jonkers et al. reported that the rate of fecal incontinence, which was $59 \%$ in the preoperative period, decreased by $14 \%$ in the postoperative period (20). In a systematic review of VR, it was reported that improvement in the fecal incontinence score ranged from $45 \%$ to $95 \%$ in the short-term followup after LVR (2). In the current study, WIS was used to evaluate the incontinence status of the patients. When the preoperative and postoperative WISs were compared, a statistically significant difference was found in terms of incontinence after LVR $(\mathrm{p}=0.002)$, which is in agreement with the literature.

The important limitations of this study are the small number of patients in the sample and the short postoperative follow-up period.

\section{CONCLUSION}

Considering the short-term results of the patients who underwent LRV for RP, LVR presents as a good option in this patient group, with a low recurrence rate and satisfactory improvement in incontinence.

\section{ETHICAL DECLARATION}

Ethics Committee Approval: The study was started after receiving approval from the No 1 Clinical Research Ethics Committee of Ankara City Hospital (Date: 03.11.2021, Decision No: E1-21-2123).
Informed Consent: Because the study was designed retrospectively, no written informed consent form was obtained from patients.

Referee Evaluation Process: Externally peer-reviewed.

Conflict of Interest Statement: The authors have no conflicts of interest to declare.

Financial Disclosure: The authors declared that this study has received no financial support.

Author Contributions: All of the authors declare that they have all participated in the design, execution, and analysis of the paper, and that they have approved the final version.

\section{REFERENCES}

1. Soare C, Lasithiotakis K, Dearden H, Singh S, McNaught C. The surgical management of rectal prolapse. Indian J Surg 2020: 1-7.

2. Samaranayake C, Luo C, Plank A, Merrie A, Plank L, Bissett I. Systematic review on ventral rectopexy for rectal prolapse and intussusception. Colorectal Dis 2010; 12: 504-12.

3. Emile SH, Elfeki H, Shalaby M, Sakr A, Sileri P, Wexner SD. Outcome of laparoscopic ventral mesh rectopexy for fullthickness external rectal prolapse: a systematic review, metaanalysis, and meta-regression analysis of the predictors for recurrence. Surg Endosc 2019; 33: 2444-55.

4. Nacion AJD, Park YY, Kim HS, Yang SY, Kim NK. Surgical treatment of rectal prolapse: a 10-year experience at a single institution. J Minim Invasive Surg 2019; 22: 164-70

5. Leventoglu S, Mentes B, Balci B, Yildiz A. Surgical techniques for rectal prolapse. Gastroenterol Insights 2021; 12: 310-8.

6. Bordeianou L, Paquette I, Johnson E, et al. Clinical practice guidelines for the treatment of rectal prolapse. Dis Colon Rectum 2017; 60: 1121-31.

7. Loh KC, Umanskiy K. Ventral Rectopexy. Clin Colon Rectal Surg 2021; 34: 62-8.

8. Tsunoda A, Takahashi T, Matsuda S, Oka N, Kusanagi H. Midterm functional outcome after laparoscopic ventral rectopexy for external rectal prolapse. Asian J Endoscopic Surg 2020; 13: 25-32.

9. Mäkelä-Kaikkonen J, Rautio T, Kairaluoma M, et al. Does ventral rectopexy improve pelvic floor function in the long term? Dis Colon Rectum 2018; 61: 230-8.

10. $\mathrm{Fu} \mathrm{CW}$, Stevenson AR. Risk factors for recurrence after laparoscopic ventral rectopexy. Dis Colon Rectum 2017; 60: 17886.

11. Jorge JMN, Wexner SD. Etiology and management of fecal incontinence. Dis Colon Rectum 1993; 36: 77-97.

12. Ahmad NZ, Stefan S, Adukia V, Naqvi SAH, Khan J. Laparoscopic ventral mesh rectopexy: functional outcomes after surgery. Surg J 2018; 4: e205-e11.

13. Lundby L, Iversen LH, Buntzen S, Wara P, Høyer K, Laurberg S. Bowel function after laparoscopic posterior sutured rectopexy versus ventral mesh rectopexy for rectal prolapse: a double-blind, randomised single-centre study. Lancet Gastroenterol Hepatol 2016; 1: 291-7.

14. Maggiori L, Bretagnol F, Ferron M, Panis Y. Laparoscopic ventral rectopexy: a prospective long-term evaluation of functional results and quality of life. Tech Coloproctol 2013; 17: 431-6.

15. Tsunoda A. Surgical treatment of rectal prolapse in the laparoscopic era; a review of the literature. J Anus Rectum Colon 2020; 4: 89-99. 
16. Gleditsch D, Wexels WA, Nesbakken A. Surgical options and trends in treating rectal prolapse: long-term results in a 19-year follow-up study. Langenbeck's Arch Surg 2018; 403: 991-8.

17. Steele SR, Goetz LH, Minami S, Madoff RD, Mellgren AF, Parker SC. Management of recurrent rectal prolapse: surgical approach influences outcome. Dis Colon Rectum 2006; 49: 440-5.

18. Tsunoda A, Takahashi T, Ohta T, Fujii W, Kusanagi H. Newonset rectoanal intussusception may not result in symptomatic improvement after laparoscopic ventral rectopexy for external rectal prolapse. Tech Coloproctol 2016; 20: 101-7.

19. Madbouly KM, Youssef M. Laparoscopic ventral rectopexy versus laparoscopic wells rectopexy for complete rectal prolapse: long-term results. J Laparoendosc Adv Surg Tech 2018; 28: 1-6.

20. Jonkers HF, Maya A, Draaisma W, Bemelman W, Broeders I, Consten E, et al. Laparoscopic resection rectopexy versus laparoscopic ventral rectopexy for complete rectal prolapse. Tech Coloproctol 2014; 18: 641-6. 